INDO GLOBAL JOURNAL OF

PHARMACEUTICAL SCIENCES

ISSN 2249- 1023

\title{
Accumulation of GABA Reduces Lsi-1 and Lsi-2 Gene Expressions and Modulates the Antioxidant Responses in Oryza sativa to Provide Tolerance Towards Arsenic
}

\author{
Navin Kumar ${ }^{1,2^{*}}$, Saripella Srikrishna ${ }^{2}$, Shekhar Mallick ${ }^{1^{*}}$ \\ ${ }^{1}$ CSIR- National Botanical Research Institute, Lucknow, India \\ ${ }^{2}$ Department of Biochemistry, Faculty of Science, Banaras Hindu University, Varanasi, India \\ Address for Correspondance: Navin Kumar, navinmsbc@gmail.com ; Shekhar Mallick, shekharm@nbri.res.in
}

Keywords GABA;

Arsenic;

Transporter;

Antioxidants.

\begin{abstract}
Aminobutyric acid (GABA) is a non-protein four carbon amino acid, which counteract instantly against wide range of biotic and abiotic stresses in plant through regulation of GABA shunt pathway. Although, GABA assisted tolerance against metalloid toxicity in plants is largely unexplored. We have examined GABA induced tolerance in rice seedlings with two GABA concentrations i.e., 50 and $100 \mu \mathrm{g} \mathrm{ml}-1$. Results showed that accumulation of GABA reduced the expressions of Lsi-1 and Lsi-2 transporter genes, which ultimately decreased the accumulation of As in rice seedlings. The accumulation of GABA also modulated the gene expression of GABA shunt pathway and activity of antioxidant enzymes, which strongly induced the tolerance in plants. Antioxidant enzymes such as CAT, POD, GPX and SOD showed maximum alteration in activity with GABA accretion. In both the exposure, lower level of GABA was highly efficient to provide tolerance in the plants against As(III), while higher level of GABA was slightly toxic. Oxidative stress marker such as TBARS and $\mathrm{H} 2 \mathrm{O} 2$ contents were reduced with GABA accumulation. These results suggested that GABA sturdily inhibits As accumulation and provides tolerance towards As(III). The genetic manipulation of GABA related genes would be the future prospects of plant those deal with contamination for survivorship. (C) 2016 iGlobal Research and Publishing Foundation. All rights reserved.
\end{abstract}

Conference Proceedings: International Conference on Advances in Plant and Microbial Biotechnology (PMB2017); JIIT, Noida: February 02-04, 2017

Indo Global Journal of Pharmaceutical Sciences( ISSN 22491023 ; CODEN- IGJPAI; NLM ID: 101610675) indexed and abstracted in EMBASE(Elsevier), SCIRUS(Elsevier),CABI, CAB Abstracts, Chemical Abstract Services(CAS), American Chemical Society(ACS), Index Copernicus, EBSCO, DOAJ, Google Scholar and many more. For further details, visit http://iglobaljournal.com 